\title{
The Study on Green Energy-saving Buildings Design
}

\author{
Li Weifang \\ School of Management, Wuhan University of Science and Technology, Wuhan, 430081, China
}

KEYWORD: Green Buildings; Energy-saving; Design; Implementing Proposals

ABSTRACT: As advocating a low-carbon lifestyle and increasing resources crisis, the green energy-saving buildings have profound implications for our country's development and environment protection. Analyzing key techniques of energy-saving about green buildings from design link, because of design is a starting point for green buildings. In China, there are some problems in energy-saving design of green buildings because of lacking in experience and still immature technology. In order to improve the design quality of green energy-saving buildings, positive passive techniques and high efficient active techniques and design ideas according to local conditions should be adopted in China.

\section{Introduction}

The promotion of green energy-saving buildings is a not only complicated and integrity system, but a also hard long-term task. The problems of environment and resource have been given more attention, buildings construction consume large resources and cause major contamination. According to investigation statistics, about $50 \%$ harmful substances that drive global warming result in buildings construction and operation. Building energy consumption accounts about $30 \%{ }^{[1]}$ To reduce resource pressures and environment pollution, the promotion of green energy-saving buildings should be necessary.

For the energy is in short supply, the ideas of save energy and reduce the cost should be paid the most attention during the buildings design. The implementation of ideals of green energy-saving during the buildings design involves many links such as design plan, construction and operation. Considering advantage of green energy-saving buildings, the energy-saving design of buildings has become one of the most pressing issues that construction industry must face. Analyzing key techniques of energy-saving about green buildings from design link, because of design is a starting point for green buildings. Upholding the concept of "based by passive technology, supplemented by active technology", the design plan of green energy-saving buildings should be according to local conditions, improving energy efficiency in buildings, full utilization of renewable energy, in order to reduce buildings energy consumption, realize rational allocation of energy resources.

\section{The theoretical basis of green energy-saving buildings design}

\section{The definition of green energy-saving buildings}

From the concepts, green energy-saving buildings use natural energy such as sunlight, wind and so on, applied to buildings design and construction, in order to boost coordination with surrounding environment and buildings, to reduce environment pollution and energy consumption at the extreme. During the design of green energy-saving buildings, non-pollution and energy-saving should be paid more attention. Especially for interior design, design personnel should know how to use the sun, creating opportunities of being closer to nature for residents. The ultimate goal of green energysaving buildings design is to achieve the state of man, nature, environment and buildings as well as a harmonious relationship among them, through the buildings design to create a way of life. So, at this stage, the design of green energy-saving buildings what we say should reduce nature's loss, meet the demands to the function of the buildings, under the conditions of environmental protection and energy saving.

\section{The current situations of global and China buildings energy consumption}

As one of the main parts of global energy consumption, the proportion of buildings energy consumption in developed countries is far greater than the proportion in developing countries. There are some causes of this phenomenon such as fairly strong economy, high requirement of living standards in developed countries, having enough ability to pay for the buildings energy consumption. Taking Ameri- 
ca as an example, the country's energy consumption in recent years accounted for more than $1 / 5$ of the global energy consumption, in America the energy consumption in buildings operational stage accounted for about $1 / 10$ of global energy consumption.

In China, the present electricity consumption in urban resident buildings operational stage accounted for about $22 \%$ 24\% of the country's total generation capacity. Buildings energy consumption accounted for about $21 \%$ 24\% of the national commercial energy. Above data only involve buildings operational stage, without energy consumption of making building materials and building construction. ${ }^{[1]}$

\section{The evaluation standard of green energy-saving buildings}

The design of green energy-saving buildings should pay attention to the evaluation standard of green energy saving buildings, in order to ensure the designed buildings to meet user requirements. For the evaluation standard, green buildings act as evaluation subject, evaluation principles includes " 4 saving and 1 environment protected". From six aspects, whether the buildings meet the green buildings requirements should be judged, including land saving and outdoor environment, energy saving and resource utilization, water saving and water reuse, material saving and resources utilization, the quality of outdoor environment and operation management.

\section{The main ways to energy conservation of green buildings}

The way of building energy conservation mainly includes two aspects. 1) Active energy saving way. It refers to that high efficiency and low consumption construction equipment in building operation in order to reduce energy consumption. 2) Passive energy saving way. It refers to reducing or canceling the construction equipment, through other ways without using the construction equipment can reduce energy consumption. By directly using existing climate and environment, such as wind, solar energy, ambient temperature and humidity, vegetation, site selection and so on, through integration of above these conditions and buildings design, the goal of reducing building energy consumption can be achieved.

\section{The main problems of green energy-saving building design}

The aim of the design of green energy-saving buildings is to strictly control the building energy consumption problem in use. Therefore, without violating the basic premise of the law of natural climate, thinking about the fusion of internal and external influencing factors of buildings, the study on the design of low energy consumption building is necessary. At the present, because of fast development of industrialization and urbanization in China, and building energy consumption accounts for a large part of the social total energy consumption, the target of saving energy and reducing consumption should be embedded in the early of the buildings design. Nevertheless a lot of problems emerge in actual buildings energy efficiency design. The main contents are as follows.

\section{Single energy-saving buildings design planning}

The current energy-saving design planning application in the buildings design process is relatively single, just show the improved heat preservation measures in the application of the building envelope, both design method and design approach are relatively inadequate.

\section{The cost of investment does not match the actual energy saving requirements}

Although some buildings at the beginning of design had considered the problem of green energysaving, and paid attention to the screening of material day lighting and heat preservation effect. However, the costs of construction in practice are not considered. As a result, the construction costs are greatly improved. Based on such, in the process of construction, the construction unit will change the design of green energy-saving, considering from cost. So this makes it hard to achieve the desired energy saving effect. ${ }^{[2]}$ 


\section{The local characteristics of buildings and climate environment in this region are lack of har- mony and unification}

"Adjust measures to local conditions" is the one big characteristic of green building design, particular focusing on the integration of the green building, regional features, climate environment in existing green building design. The following several aspects may be encountered: 1) Stiff splicing green building technology. 2) Blindly overlaying energy efficient equipment. 3) Lacking of good design habits. 4) The lack of consideration of local characteristics and climate factors.

\section{Some suggestions on design of green energy-saving buildings}

\section{Carrying out the overall and planning to the energy-saving buildings}

For the buildings design, before the overall planning of the buildings, the designers should explore the site investigation, mainly surveying the buildings environment, including river, winds, sunlight, etc. And the designers should detect local resource, based on the requirements of the buildings design, carrying out the overall and planning to the energy-saving buildings. Meanwhile, through the computer simulating techniques, the designers should analyze outdoor wind environment, sunshine, day lighting of the buildings, in order to determine the best green energy-saving design scheme of the buildings. For instance, synthetically considering the surrounding public facilities, in order to facilitate travel and improve the utilization level of the public service facilities, the designers should carry out the overall and plan the design of green energy-saving buildings.

\section{Adopting positive passive techniques in the design of green energy-saving buildings}

In passive design, the designers should design seal casings for the buildings, it is almost impossible to get or lost any heat. The designers should adopt ultra thick thermal blanket material, complex doors and windows, in order to achieve efficient thermal insulation and thermal insulation capabilities by buildings structural reasons, almost without the use of active energy. Even if the other sources of energy are needed, as far as possible, the designers should adopt clean renewable energy. On the basis of guarantee the buildings comfort, the buildings should achieve the goal of lower energy consumption. Envelop isolation characteristic is the foundation of reducing energy buildings consumption, so adopting envelop with good energy saving effect is critical passive techniques in the design of green energy-saving buildings. It should be paid attention to the following aspects in passive design:

New type thermal-insulating material for building outer walls should be enthusiastic adopted. The external insulation technology is one of buildings energy efficiency technology. Because envelope has the characteristics of big energy loss, the walls take a big part of envelope. Energy efficiency technology for the walls should be expanded, and new type energy saving materials should be adopted.

The selection of roof materials should deserve more attention. Because the heat transfer loss of buildings roof account for about $9 \%$ of the heat transfer loss of buildings envelope, strengthening the roof heat preservation and heat proof quality can reduce energy consumption. The traditional roof materials have some features on poor thermal insulation, more heat loss, difficult construction, slowly moving, etc. As a result of waterproof and insulation technology, the roof thermal insulation layers should be researched and promoted. With the continuous development of technology and materials craft, some new materials such as polystyrene should be used with further development. These should provide the basis and premise for the design of insulation roof system.

High performance windows and doors should be studied and utilized. At design, designers should think about the main factors which affect the window heat transfer coefficient and sealing performance such as profiles, glass, sealing performance, windows form and so on. Foam insulation materials should be added at the seams between window frame and buildings, in order to reduce heat loss through air infiltration. What apply more extensive at present are PVC door \& window, aluminumplastic door \& window, FRP door \& window, etc. The properties of glass have the most impact on energy-saving effect of door \& window. At present, the energy-saving glasses apply in buildings mainly include insulating glass, vacuum glass, coated glass, etc. Insulating and vacuum glass are outstanding in energy-saving. Heat reflection coated glass and low radiation coated glass are new energy efficiency glass while improved technology in recent years. 
The design of the buildings wall should be paid more attention. The building wall for construction project has a very important role. It is a barrier layer for indoor \& outdoor space. There is a direct connection between the change of indoor space and the design of wall area and structural. So in the energy- saving buildings, the design of the buildings wall should be paid more attention.

\section{Adopting high efficient active techniques in the design of green energy-saving buildings}

Active techniques achieve buildings energy efficiency through optimizing and choosing equipment systems. Passive techniques and active techniques are complementary, the former can reasonably save energy consumption, the latter can reduce the building energy consumption even further. Shown in Table 1, Heating and air condition, light of active techniques are the main contributors to buildings consumption at present. From the design view of broadening sources and reducing use, reducing their energy consumption is one of the key techniques for active techniques. ${ }^{[3]}$

Table 1. The composition of Buildings energy consumption

\begin{tabular}{|l|l|}
\hline Energy consumption & Proportion \\
\hline Heating and air condition & $65 \%$ \\
\hline Hot water & $15 \%$ \\
\hline Electric lighting & $14 \%$ \\
\hline Cooking & $6 \%$ \\
\hline
\end{tabular}

In active design, efficient buildings supply energy equipment and system should be adopted. The designers should select high efficiency and energy saving products demanded by our country, strictly according to design standard and energy saving measures. For example, the indoor unit of the air conditioner should be adopted high efficiency compressor and motor.

Green lighting project should be promoted. In illumination design, the designers should rationally design and choose lighting lamps in order to achieve the goal of green illumination. Through district centralized control, lighting lamps are zone control. While scene-setting, scene lighting panel should be installed. And person may adjust light in order to achieve energy efficiency and express humanities.

Using energy systems should be optimized. Buildings using energy systems involve cold and heat sources, efficiency of transmission, using energy ends. Using energy systems should be studied systematically as the whole, by integration technologies, in order to improve energy efficiency.

Energy structure should be adjusted, developing new energy and renewable energy. Large-scale application of renewable energy such as solar energy, shallow geothermal energy should be promoted vigorous development in buildings. Solar energy has always been one of the most popular renewable energy in design of green energy-saving buildings. Generally, in energy-efficient design, the designers select energy structure, according to the characteristics of the solar heat collection. For example, using solar energy to replace roof covering can achieve the purpose of saving investment.

\section{The design of green energy-saving buildings should be adjusted measures to local conditions}

In energy-saving design, two characteristics need special attention. One is regional differences. Due to different geographical climate environment, varying the user habits, difference of corresponding to the buildings form, the demand for buildings energy efficiency technology has a certain gap. The other is process control. Even if in the similar conditions, the buildings energy consumption can vary at different times. In the design, the buildings energy efficiency design should be adjusted to local conditions and people's needs. ${ }^{[4]}$

\section{Economy should be paid attention in the design of green energy- saving buildings}

Through the choice of appropriate technologies, the design of passive technology priority and initiative optimize, the economy of green energy- saving buildings can be achieved, based reducing incremental costs as possible. From the point of full life-cycle, incremental costs may be recycled by reducing the operating costs in 5 7 years. 


\section{Conclusions}

The design of green energy-saving buildings involves the whole process of projects. At the beginning of design, the integrated design method should be introduced, which is sustainable design supported by economy returns on investment. In the design of green energy-saving buildings, how to reduce energy consumption and achieve energy recycling is the main direction of design. In design of green energy-saving buildings, the relationship between the energy loss and economic benefits should balance, in order to achieve the greatest impact in energy efficiency, without impacting on buildings quality and functionality, environmentally friendly.

\section{References}

[1]Buildings Energy Conservation Research Center of Tsinghua University, 2012 China Annual Development Report about Energy Efficiency Buildings, China Architecture \& Building Press, 2012: 2 4,11

[2] Duan haitao, Some Suggestions on Green Energy Efficiency Buildings Design, Development Guide to Building Materials, 2015,(2):131 132

[3] Kang Shouhe, The Discuss of Key Technology about Green Energy- saving Design Based on the Architectural Design and Operation Management, Shanxi Architecture, 2015,41(4):203 204

[4] Ren Haibin, The Discuss of Green Energy-saving Design of Modern Architecture, Shanxi Architecture, 2013,(2):201 